\title{
Use of Ground Penetrating Radar for Assessing Interconnections between Root Systems of Different Matured Tree Species
}

\author{
Livia Lantini ${ }^{1}$, Rich Holleworth ${ }^{2}$, Daniel Egyir ${ }^{1}$, Iraklis Giannakis ${ }^{1}$, Fabio Tosti ${ }^{1}$, Amir M. Alani ${ }^{1}$
}

\begin{abstract}
${ }^{1}$ School of Computing and Engineering, University of West London (UWL), St Mary's Road, Ealing, W5 5RF, London, UK, 21380119@student.uwl.ac.uk; Daniel.Egyir@uwl.ac.uk; Iraklis.Giannakis@uwl.ac.uk; Fabio.Tosti@uwl.ac.uk; Amir.Alani@uwl.ac.uk

${ }^{2}$ London School of Film, Media and Design, University of West London (UWL), St Mary's Road, Ealing, W5 5RF, London, UK, Rich.Holleworth@uwl.ac.uk
\end{abstract}

\begin{abstract}
This study presents recent advances achieved in the use of ground penetrating radar (GPR) for the health monitoring of tree root systems. The main objectives of the research were to provide an effective and high-resolution mapping of the root systems belonging to different species of matured trees, as well as to investigate areas of roots interconnection. To this purpose, a data processing methodology based on three main stages was developed. A preprocessing algorithm was first proposed to remove noise-related information from the raw data and to enhance deep reflections from attenuated targets. Afterwards, an algorithm for identification of targets (i.e. the vertices of the reflection hyperbolas) and their automated tracking in a threedimensional environment was developed. A third stage was focused on estimating tree root density with emphasis on the interconnection area. To test the feasibility of the proposed methodology, the soil around two different tree species (i.e. maple and ash trees) was investigated using a ground-coupled GPR system equipped with a $700 \mathrm{MHz}$ central frequency antenna. The method has proven to identify distinctive features of both trees, in terms of shallow (i.e. within the first $25 \mathrm{~cm}$ from the soil surface) and deep (i.e. deeper than $25 \mathrm{~cm}$ from the soil surface) root systems. In addition, results have allowed to assess how different root systems interact with each other.
\end{abstract}

Keywords-ground penetrating radar (GPR), tree health monitoring, tree roots detection, tree roots interconnection, data processing methodology

\section{INTRODUCTION}

Sustainable management of forestry heritage is nowadays a crucial task to be pursued among government organisations. The focus is mostly on rare, ancient and mature trees, as they are a natural and historic asset to be preserved [1]. Within this context, the monitoring of tree roots is crucial for identifying potential damages and early decays. The estimate of root systems architecture is essential for several disciplines, ranging from botanic and arboricultural practices to highway engineering, dealing with the issue of interference between roads and trees.

Tree roots are usually organised in complex systems, and they can be fundamentally distinguished into woody and nonwoody roots. Woody roots have undergone secondary growth, resulting in a more rigid structure. These roots have a structural role, being mainly responsible for anchoring the tree in the ground [2]. Wilson [3] observed that woody roots located within one or two meters from the stem (i.e., the so- called zone of rapid taper) have different features from roots located beyond this area. This is related to the considerable secondary thickening exhibited by woody roots. Differently, woody roots located further from the trunk are also responsible for gathering water and nutrients. Their size is often influenced by mechanical stress, e.g., the wind load [4]. In contrast, non-woody roots, also referred to as fine or absorbing roots, are responsible for the absorption of water and nutrients [2], the root hormone synthesis and the symbiosis with soil microorganisms. These roots are not subject to secondary thickening, and they are generally small in diameter $(<2 \mathrm{~mm})$ with a lifespan ranging from days to weeks, depending on soil conditions and temperature [2].

Tree roots are responsible for water and minerals uptake, carbohydrates storage, and hormonal signalling [2], as well as for providing support and anchorage in the ground [5]. Therefore, the health of the root system, and consequently the health of the tree, is strictly related to the soil environment [6]. Hence, root functioning can be compromised in soils where the provision of these resources is not sufficient. Moreover, an increase in air pollution, together with the advent of unknown pathogens carried along by the wind, has led to an increment in tree diseases [7]. Such microorganisms can spread rapidly, leading to the infection and the death of entire forests [8]. In more detail, tree roots can be attacked by parasitic fungi, resulting in the loss of the terminal roots, with severe consequences on the tree survival [9]. To this effect, proper assessment of tree root systems is compulsory to detect early decay and carry out effective remedial actions.

Within this framework, destructive testing methods for root detection and mapping mostly reveal as not suitable for the assessment of living trees; besides, they are acknowledged as costly and time-consuming, and they can provide only local information. On the contrary, non-destructing testing (NDT) methods are becoming popular for the preservation of natural heritage, due to their high productivity and overall reliability of the information produced [10]. Among these techniques, ground penetrating radar (GPR) is gaining attention in view of the high versatility, rapidity of data collection and the reliability of results at relatively limited costs. It has been extensively used for applications in various disciplines, such as archaeological investigations [11], bridge deck analysis [12], detection of landmines [13], civil and environmental engineering applications [14], and planetary exploration [15]. The use of GPR in forestry applications is commonly related to the assessment of tree trunks, tree root mapping and the 
evaluation of tree-soil interaction. Regarding the investigation of tree roots, the first application of GPR dates back to 1999 and refers to the mapping of tree root systems [16]. From that time onward, research has mostly focused on the assessment of root diameter [17], biomass [18], coarseness [19] and pattern in urban areas [20]. Moreover, recent studies have further investigated the capabilities of GPR in estimating tree root system architecture [21, 22].

\section{AIMS AND OBJECTIVES}

The aim of this research was to demonstrate the potential of GPR in providing an effective and high-resolution mapping of root systems of different tree species and areas of roots interconnection.

To achieve this aim, the main objective was to develop a data-processing methodology for a three-dimensional (3-D) visualisation of shallow and deep tree root systems as well as for getting information about the density of roots at the interconnection area.

\section{Methodology}

\section{A. The Survey Technique}

The soil between a maple tree (trunk circumference of 1.91 $\mathrm{m}$ and average radius of $0.30 \mathrm{~m}$ ), and an ash tree (trunk circumference of $0.98 \mathrm{~m}$ and average radius of $0.156 \mathrm{~m}), 6.7$ $\mathrm{m}$ distant from each another, was investigated (Fig. 1).

A number of 20 semi-circular scans, located $0.30 \mathrm{~m}$ from one another, were carried out around a maple tree trunk, starting at $0.50 \mathrm{~m}$ from the outer surface of the bark. Hence, an overall area of $65.43 \mathrm{~m}^{2}$ was covered with an outer radius of $6.50 \mathrm{~m}$ and an inner radius of $0.80 \mathrm{~m}$. Similarly, 5 circular scans, at $0.30 \mathrm{~m}$ intervals, were performed all around the ash tree circumference starting at $0.80 \mathrm{~m}$ from the outer surface of the bark. To this effect, an overall area of $11.73 \mathrm{~m}^{2}$ with an outer radius of $2.16 \mathrm{~m}$ and an inner radius of $0.96 \mathrm{~m}$ was covered. The survey scheme was arranged to create a common area of survey (overall area of $5.37 \mathrm{~m}^{2}$ ) where potential interconnections between the two root systems were investigated.

A ground-coupled GPR system (Opera Duo, IDS Georadar), equipped with $700 \mathrm{MHz}$ and $250 \mathrm{MHz}$ central frequency antenna was used for testing purposes. Data were acquired using a time window of $80 \mathrm{~ns}$ and 512 samples.

The horizontal resolution was set to $3.2 \times 10^{-2} \mathrm{~m}$. In order to achieve the highest effective resolution, only the $700 \mathrm{MHz}$ frequency was considered for data processing purposes.

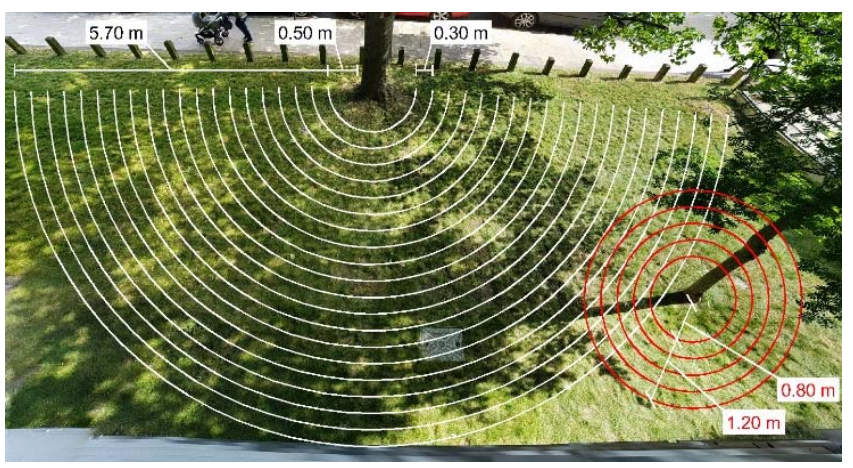

Fig. 1. The surveyed area.

\section{B. The Signal Processing Scheme}

Three main sequential data-processing stages were proposed. A pre-processing algorithm for signal noise reduction and amplification of deeper targets was first developed, in order to enhance the visualisation of the reflection hyperbolas and to help operators and decisionmakers with the interpretation of enhanced GPR images. A multi-stage algorithm for the identification of tree roots and their sequential tracking in a 3-D domain was defined subsequently. A relationship for the estimation of tree root density was finally proposed.

\section{a) Pre-processing algorithm}

Main aim of this stage is to minimise clutter-related information in GPR data. Moreover, data analysis and interpretation are needed to extract quantifiable wave properties for conversion into application-specific information. To provide an expeditious and broad-ranging applicability of the proposed algorithm, only the main signal processing techniques were considered. This allows applicability of the algorithm to different types of data, minimising the risk of distorted information due to overprocessing of data. To this purpose, sequential use of a) zerooffset removal, b) background removal, c) bandpass filtering and d) time-varying gain was carried out.

\section{b) Tree root tracking algorithm}

The methodology followed for the development of this stage of the algorithm is composed of two main steps.

First, preliminary assumptions (i.e., data acquisition method and dielectric properties of the medium) and data input (i.e., outcomes of pre-processing algorithm, matrix dimensions, GPR data acquisition settings) were defined.

Subsequently, data from the pre-processing stage are processed following an iterative processing method, based on the comparison between amplitude values at a given position of the 3-D domain and a given threshold.

- Target detection: the algorithm compares the amplitude values all over the GPR data domain with a threshold value. This step is needed to identify the apices of reflection hyperbolae (i.e., apices of roots), filtering out amplitude values not likely related to tree roots.

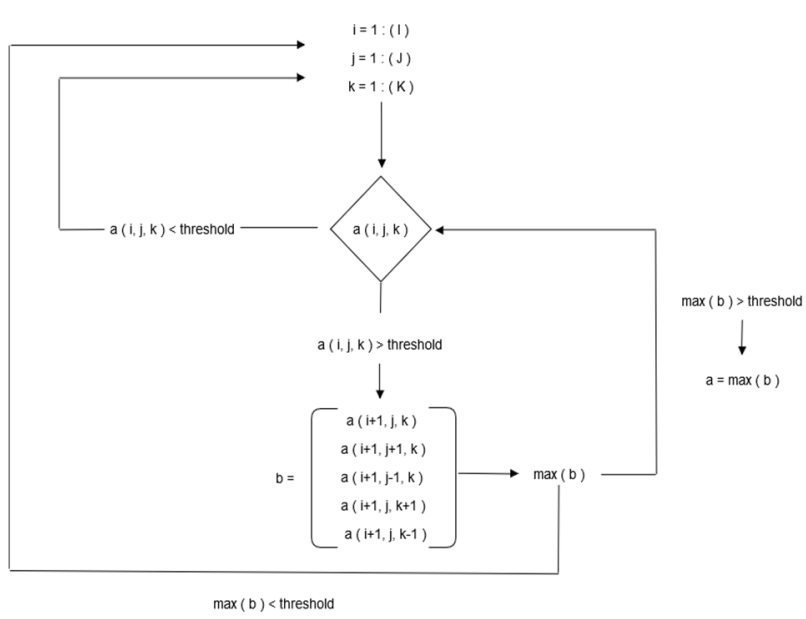

Fig. 2. Flow chart representing the functioning of the tree root tracking algorithm 
- Correlation analysis: other vertices are investigated in the neighbourhood of that identified at the previous step, to look for potential amplitude values greater than the threshold.

- Tracking of the root: the algorithm follows the vertices of the hyperbolae, creating a vector that corresponds to a single root.

- Reconstruction of root sistem architecture in the 3-D domain: vectors created at the previous step are positioned in a 3-D rendering of the tree root system, to provide a comprehensive visualisation of the root system.

\section{c) Root density estimation}

A dedicated index was provided to achieve information about density of roots at the interconnection area (e.g., local changes of density). First, best-fitting functions were used to better approximate root paths in the 3-D domain as well as to identify length of each root in a continuous domain. Hence, the domain was divided into reference volume units with dimensions of $0.3 \mathrm{~m} \times 0.3 \mathrm{~m} \times 0.3 \mathrm{~m}$. Length of roots insisting on the reference volume was then evaluated as follows:

$$
d=\frac{\sum_{i=1}^{n} L_{i}}{V}
$$

where $d$ is the density $\left[\mathrm{m} / \mathrm{m}^{3}\right], n$ is the number of roots contained in a reference unit of volume $\left[\mathrm{m}^{3}\right]$ and $L_{i}$ is the length of the root $[\mathrm{m}]$.

\section{MAIN RESULTS AND SHORT DISCUSSION}

The application of the pre-processing algorithm to the raw data allowed to increase the signal-to-noise ratio and enhance target detections (i.e., hyperbolae). In addition, the in-depth position of the apices of the hyperbolae were located. Fig. 3 shows a comparison between B-scans before (Fig. 3(a)) and after (Fig. 3(b)) the application of the dedicated signal processing algorithm. It can be noticed how the visualisation of deeper target has been enhanced by the application of signal processing techniques.

Hence, the application of the multi-stage data processing methodology allowed to locate targets in the 3-D domain and to automatically track their development. Fig. 4 shows the results of the algorithm application to the maple tree area in a 2-D plan view (Fig. 4(a)) and in a 3-D rendering (Fig. 4(b)). To aid with the result interpretation, roots located within the shallow (i.e. within the first $25 \mathrm{~cm}$ of soil) and deep (i.e. below $25 \mathrm{~cm}$ of soil) subsurface are identified with different colours in the renderings.

Results have proven potential of the algorithm in finding viable root paths, as well as in identifying relevant elements connected to one another according to the logic-based and signal-noise-based instructions.

For sake of consistency, the coordinates of the points were double-checked with the positions of the hyperbola apices detected in the collected B-scans.

The application of this methodology to both the tree root systems (i.e., maple and ash trees) allowed for a more comprehensive interpretation of the interaction between roots belonging to trees of different species as well as their development in the soil. Fig. 5(a) and Fig. 5(b) show an overview of the tree root systems under investigation and a

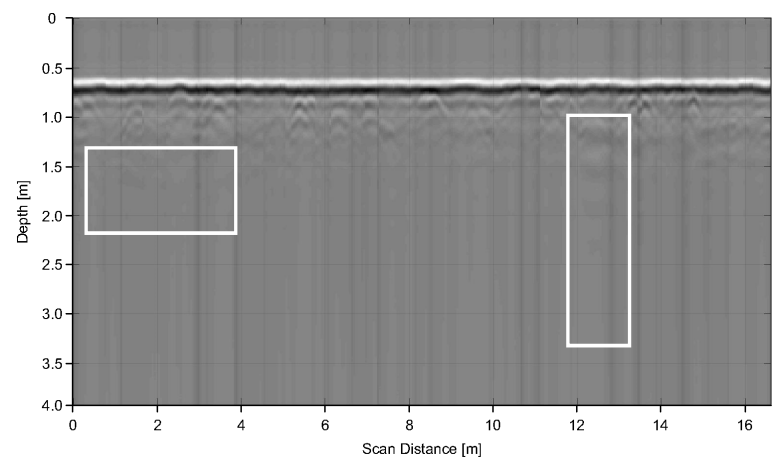

(a)

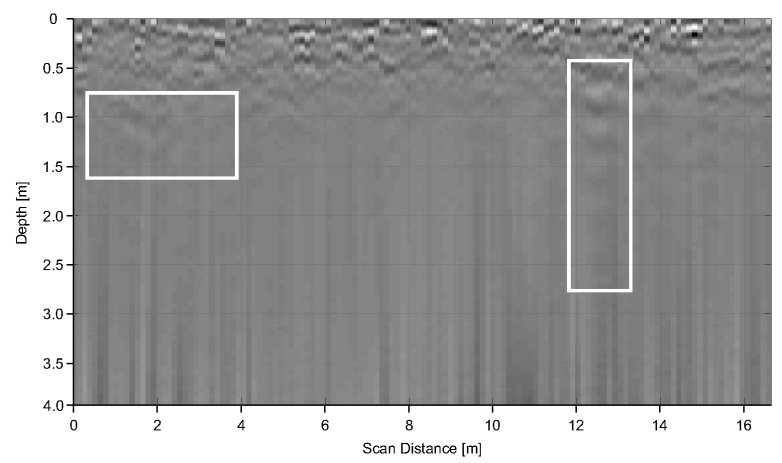

(b)

Fig. 3. An example of B-scan before (a) and after (b) the application of the pre-processing algorithm.

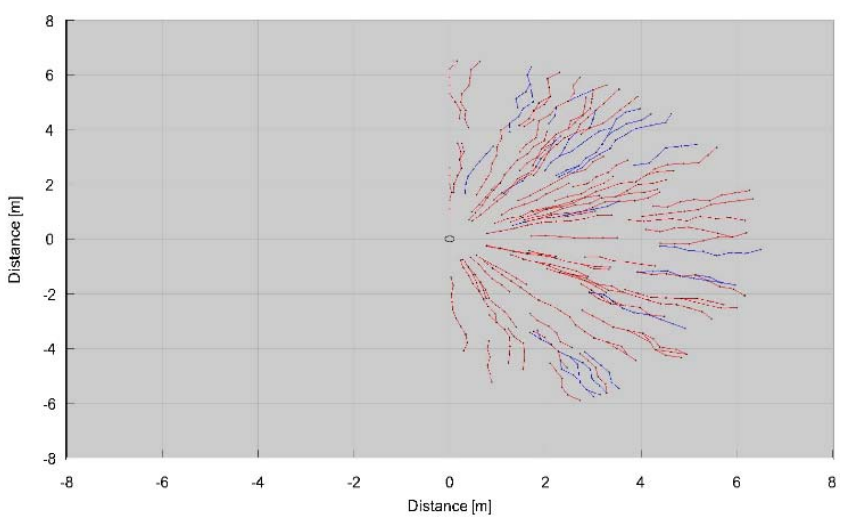

(a)

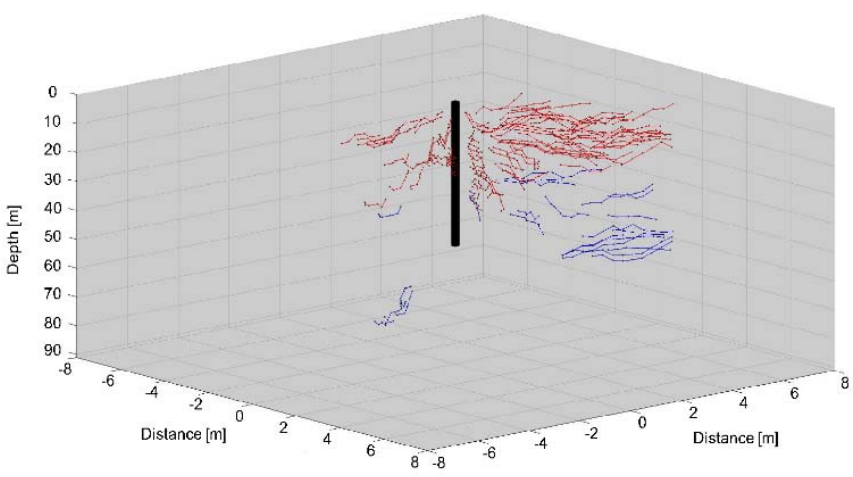

(b)

Fig. 4. Result of the application of the multi-stage data processing algorithm to the investigated maple tree in 2-D plan view (a) and in a 3-D rendering. 
detail of the interaction area between the investigated trees, respectively.

In order to elaborate on the results, a density index was proposed. This allowed to examine changes in the density of roots within the soil. The domain was divided into reference units and the total root length per reference unit was investigated. Fig. 6 presents the output of this data processing stage in form of a proxy of a density map.

In regard to the maple tree, the highest density value within the first $0.3 \mathrm{~m}$ of soil is $1.53 \mathrm{~m} / \mathrm{m}^{3}$. The highest values, ranging from $1.3 \mathrm{~m} / \mathrm{m}^{3}$ to $1.5 \mathrm{~m} / \mathrm{m}^{3}$, are located in three main zones: $x$ $=-2 \mathrm{~m} \div-1.7 \mathrm{~m}, y=3 \mathrm{~m} \div 3.3 \mathrm{~m} ; x=0.1 \mathrm{~m} \div 1 \mathrm{~m}, y=2.1 \mathrm{~m}$ $\div 3.9 \mathrm{~m} ; x=2.2 \mathrm{~m} \div 3.4 \mathrm{~m}, y=2.1 \mathrm{~m} \div 2.7 \mathrm{~m}$. It can be noted that the root density decreases as the distance from the bark increases. In fact, the density value is $0 \mathrm{~m} / \mathrm{m}^{3}$ within the zone located at $x=1.3 \mathrm{~m} \div 2.5 \mathrm{~m}, y=4.8 \mathrm{~m} \div 7.8 \mathrm{~m}$ (i.e., at the boundary of the ash tree interaction area). On the contrary, the density of roots increases locally at the interaction area between the root systems of the two trees. Indeed, parameter $d$ reaches a peak value of $2.99 \mathrm{~m} / \mathrm{m}^{3}$ within the area located at $x=2.8 \mathrm{~m} \div 4 \mathrm{~m}, y=3.9 \mathrm{~m} \div 7.8 \mathrm{~m}$.

\section{CONCLUSIONS}

This study reports ground penetrating radar (GPR)'s potential in the assessment of tree roots. The main aim of the research was to provide effective and high-resolution mapping of tree root systems, as well as to investigate the interaction between root systems belonging to different species of trees. In this regard, an estimation of the density of roots at the interconnection area was carried out.

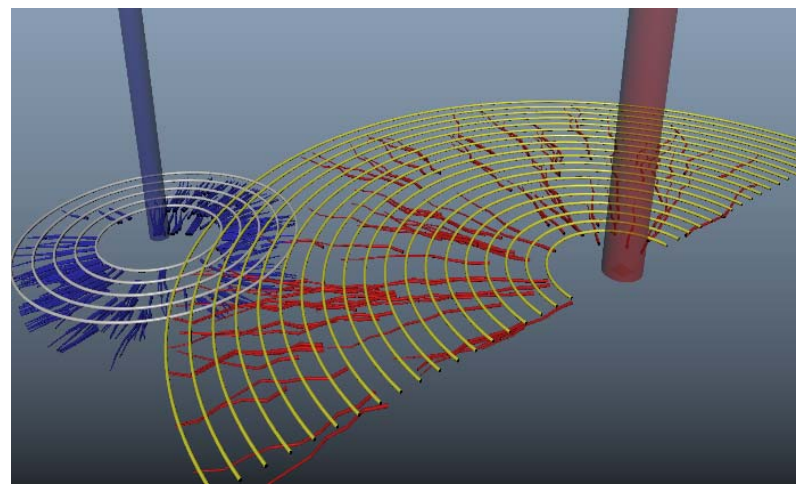

(a)

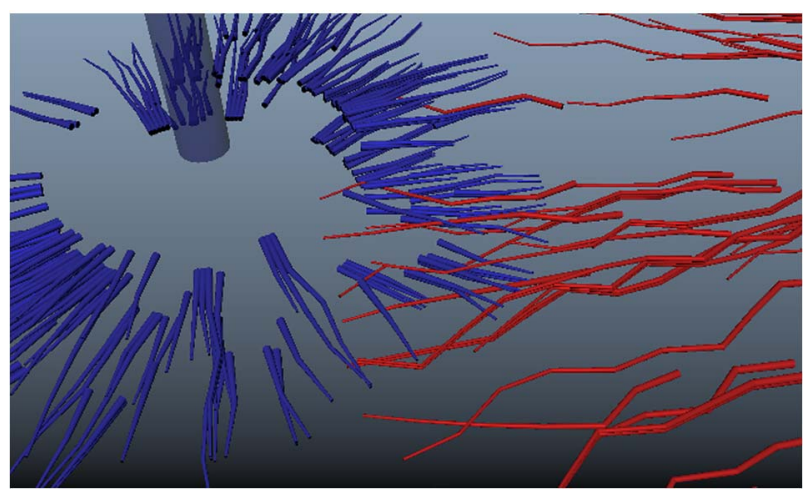

(b)

Fig. 5. Overview of the investigated tree root systems (a) and detail of the investigated interaction area (b) (red roots: maple tree; blue roots: ash tree).

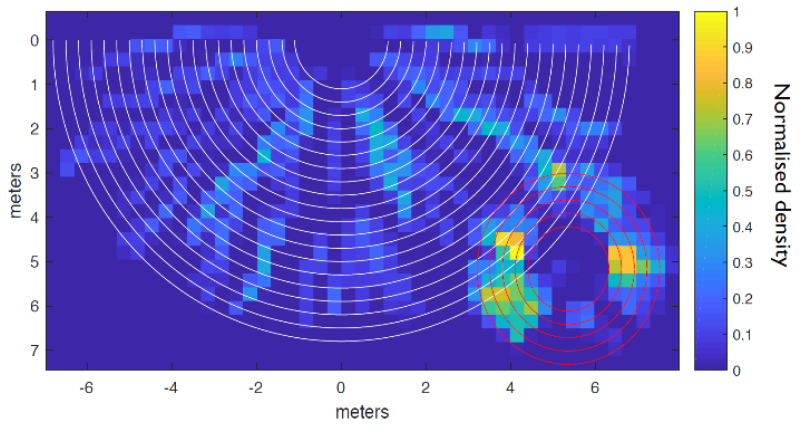

Fig. 6. GPR-derived root density map (density values are normalised)

To this purpose, the soil around two different tree species (i.e., maple and ash trees) was investigated using a GPR system equipped with a $700 \mathrm{MHz}$ central frequency antenna

A multi-stage signal processing scheme was proposed. A pre-processing algorithm for signal noise reduction and amplification of deeper targets was first developed to enhance visualisation of reflection hyperbolas as well as to help operators and decision-makers with the interpretation of enhanced GPR images. Hence, a multi-stage algorithm for location of tree roots and their sequential tracking in a 3-D domain was developed. To this effect, identification of shallow (i.e. within the first $25 \mathrm{~cm}$ from the soil surface) and deep (i.e. lower than $25 \mathrm{~cm}$ from the soil surface) root systems for both the tree species was also proven. A third main stage was focused on providing a relationship for estimation of tree root density.

Results have proven viability of the proposed algorithm in mapping root systems of different tree species. The use of a $700 \mathrm{MHz}$ central frequency antenna has proven to be suitable in detecting main root features (i.e., position of root apices and root paths) as well as in identifying areas of roots interconnection.

Shallow (i.e., within the first $25 \mathrm{~cm}$ from the soil surface) and deep (i.e., below $25 \mathrm{~cm}$ from the soil surface) root systems were also distinguished. It was also proven that density of roots increases locally at the interaction area between root systems of the two trees.

\section{ACKNOWLEDGEMENTS}

The authors would like to express their sincere thanks and gratitude to the following trusts, charities, organisations and individuals for their generosity in supporting this project: Lord Faringdon Charitable Trust, The Schroder Foundation, Cazenove Charitable Trust, Ernest Cook Trust, Sir Henry Keswick, Ian Bond, P. F. Charitable Trust, Prospect Investment Management Limited, The Adrian Swire Charitable Trust, The John Swire 1989 Charitable Trust, The Sackler Trust, The Tanlaw Foundation, and The Wyfold Charitable Trust.

\section{REFERENCES}

[1] J. L. Innes, Forest health: its assessment and status, Cab International, 1993.

[2] S. G. Pallardy, Physiology of Woody Plants, Academic Press, 2008, pp. 9-38.

[3] B. F. Wilson, Structure and growth of woody roots of Acer rubrum L., Harvard University, Harvard Forest, 1964. 
[4] A. Stokes, A. H. Fitter and M. P. Courts, "Responses of young trees to wind and shading: effects on root architecture," Journal of Experimental Botany, pp. 1139-1146, 1995.

[5] M. P. Coutts, "Root architecture and tree stability," Plant and Soil, pp. 171-188, 1983.

[6] P. J. Gregory, Plant roots: growth, activity and interaction with soils, Blackwell Publishing, 2006.

[7] A. Habermehl, "A new non-destructive method for determining internal wood condition and decay in living trees. Part 1. Principles, method and apparatus," Arboricultural Journal, pp. 1-8, 1982.

[8] R. A. Robinson, "Plant Pathosystems," in Plant Pathosystems. Advanced Series in Agricultural Sciences, Berlin, Heidelberg, Springer, 1976, pp. 15-31.

[9] B. Zak, "Role of mycorrhizae in root disease," Annual Review of Phytopathology, pp. 377-392, 1964.

[10] F. Danjon and B. Reubens, "Assessing and analyzing 3D architecture of woody root systems, a review of methods and applications in tree and soil stability, resource acquisition and allocation," Plant and Soil, pp. 1-34, 2008.

[11] D. Goodman, "Ground - penetrating radar simulation in engineering and archaeology," Geophysics, vol. 2, pp. 224-232, 1994.

[12] A. M. Alani, M. Aboutalebi and G. Kilic, "Applications of ground penetrating radar (GPR) in bridge deck monitoring and assessment," Journal of Applied Geophysics, vol. 97, pp. 45-54, 2013.

[13] D. Potin, E. Duflos and P. Vanheeghe, "Landmines GroundPenetrating Radar Signal Enhancement by Digital Filtering," IEEE Transaction on Geoscience and Remote Sensing, vol. 44, pp. 23932406, 2006.

[14] A. Benedetto and L. Pajewski, Civil Engineering Applications of Ground Penetrating Radar, Springer Transactions in Civil and Environmental Engineering, 2015.
[15] F. Tosti and L. Pajewski, "Applications of Radar Systems in Planetary Sciences: An Overview," in Civil Engineering Applications of Ground Penetrating Radar, Springer Transactions in Civil and Environmental Engineering, 2015, pp. 361-371.

[16] J. Hruska, J. Čermák and S. Šustek, "Mapping tree root systems with ground-penetrating radar," Tree Physiology, pp. 125-130, 1999.

[17] C. V. M. Barton and K. D. Montagu, "Detection of tree roots and determination of root diameters by ground penetrating radar under optimal conditions," Tree Physiology, pp. 1323-1331, 2004.

[18] J. R. Butnor, J. A. Doolittle, K. H. Johnsen, L. Samuelson, T. Stokes and L. Kress, "Utility of ground-penetrating radar as a root biomass survey tool in forest systems," Soil Science Society of America Journal, pp. 1607-1615, 2003.

[19] L. Guo, J. Chen, X. Cui, B. Fan and H. Lin, "Application of ground penetrating radar for coarse root detection and quantification: a review," Plant and soil , pp. 1-23, 2013.

[20] A. Stokes, T. Fourcaud, J. Hruska, J. Cermak, N. Nadyezdhina, V. Nadyezhdin and L. Praus, "An evaluation of different methods to investigate root system architecture of urban trees in situ: I. Groundpenetrating radar," Journal of Arboriculture, pp. 2-10, 2002.

[21] A. Alani, L. Bianchini Ciampoli, L. Lantini, F. Tosti, and A. Benedetto, "Mapping the root system of matured trees using ground penetrating radar", 17th International Conference on Ground Penetrating Radar, 18-21 Jun 2018, Rapperswil, Switzerland.

[22] F. Tosti, L. Bianchini Ciampoli, M. G. Brancadoro, and A. Alani, "GPR applications in mapping the subsurface root system of street trees with road safety-critical implications", Advances in transportation studies, vol. 44, 2018. 